\title{
Cycle lane network to connect the different campuses of Technical University of Cartagena (Spain)
}

\author{
P. Jiménez \& M. Calatrava \\ Department of Civil Engineering, \\ Technical University of Cartagena, Spain
}

\begin{abstract}
The Technical University of Cartagena consists of three campuses and two public service buildings distributed throughout the old town. This configuration causes many displacements among the different campuses, besides the daily movements between home and university. In March 2014 an online survey was undertaken on the university community (professors, students and staff) in order to know their mobility habits in relation to the mode of transport used to arrive at university and to move among campuses. The most interesting result was that for $12 \%$ of survey respondents the bike is the main mode of transport. It is a very surprising result because there is no appropriate cycling infrastructure, and the bicycle is used only by $1 \%$ of the inhabitants of Cartagena, according to general mobility patterns of the city.

As a consequence, a project about the connection of campuses by means of a suitable cycle lane network was carried out. Three designs were studied and a multicriteria analysis technique was applied to choose the best proposal, taking into account route characteristics, traffic segregation, accessibility, safety and cost. The chosen proposal was presented to the local government in order for it to be put into practice.

As a consequence, in the near future, a suitable cycle lane network to connect the different campuses of Technical University of Cartagena will be constructed. This safety cycle lane network will encourage the use of bicycles among members of the university and all inhabitants, being one of the starting points to the sustainable mobility in Cartagena.

Keywords: cycle lane network, bicycling, campuses connection, sustainable mobility, Cartagena.
\end{abstract}




\section{Introduction}

Cartagena is a medium-sized Spanish city $(218,528$ inhabitants according to the population census in 2014), which is located south-east, near to the Mediterranean Sea (see Figure 1). It is characterized by a flat terrain, with few well-located isolated slopes, and warm and dry weather. Note that, its annual average temperature is $20^{\circ} \mathrm{C}$. Therefore, Cartagena is a city with favourable conditions for bicycling.

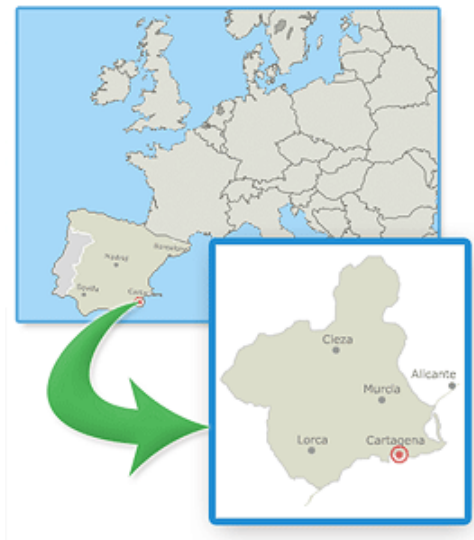

Figure 1: Geographical location of Cartagena (source: UPCT).

The aim of this project is related to the Technical University of Cartagena (UPCT), which consists of three campuses and two public service buildings distributed throughout the old town. As Figure 2 shows, these university areas and buildings are:

- Alfonso XIII campus, where schools of Agricultural Engineering, Architecture, Civil Engineering and Naval and Oceanic Engineering are located.

- Muralla del Mar campus, where schools of Industrial Engineering and Telecommunications Engineering are located, together with the innovation and research building and the laboratory buildings.

- CIM campus, where Faculty of Economic and Business Science is located.

- Rector's office building, where all administrative services and offices of the different vice chancellors are located.

- "Students' House", building where all social and cultural activities for students are realized.

Besides university buildings, the bus and railway stations should be taken into account for a future cycling infrastructure because of the numerous students, staff members and professors use them every day. 
This configuration causes many displacements among the different campuses, in addition to the daily movements between home and university, thus a mobility analysis deserves special attention.

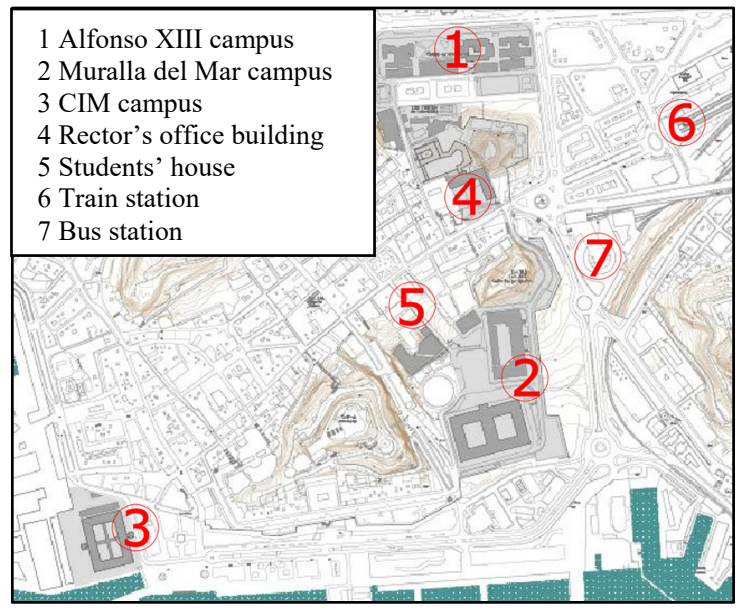

Figure 2: Technical University of Cartagena: campuses, university buildings and train and bus stations.

In March 2014 an online survey was made to the university community (professors, students and staff) in order to know their mobility habits in relation to the mode of transport used to arrive at university and to move among campuses.

The results of modal split are highlighted in Figure 3. On one hand, the main modes of transport are confirmed: walking $(40 \%)$ and car (38\%). However, on the other hand, the most interesting result is that for $12 \%$ of survey respondents the bicycle is the main mode of transport, even before public transport (8\%). Note that, in this city public transport is only composed by bus network.

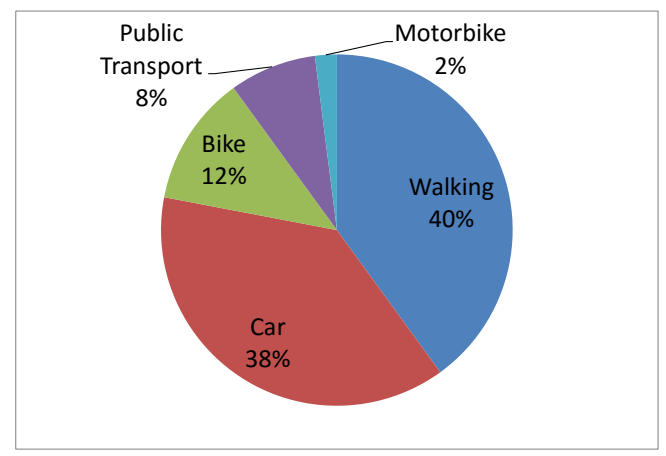

Figure 3: Modal split of university members in March 2014. 
It is a very surprising result because there are not appropriate cycling infrastructures, and bicycle is used only by a $1 \%$ of the inhabitants of Cartagena according to general mobility patterns of the city. In fact, the main result of the survey was the demand of a safe cycle lane network together with safe bike parks. Obviously, if safe cycle ways exist, the use of this sustainable, cheaper and healthy transport mode will increase, not only among university community, but also among all inhabitants in Cartagena. Thus, road traffic will decrease together with $\mathrm{CO}_{2}$ emissions, among other well-known benefits [1,2].

As a consequence, a project about the connection of campuses by means of a suitable cycle lane network was carried out. It will be the star point to achieve the general objective, that is, to integrate bicycles in the daily mobility of the city. Next, the keys of this project are explained.

\section{Design criteria}

\subsection{General design criteria}

Guidelines about cycle ways in Spanish cities have been studied as references for this project. For example, Sevilla, Vitoria o Barcelona due to their successful cycle networks [3-6], and some general guidelines about design, construction, signposting, management or parks related to cycle paths [7-9].

Once all information was processed, three types of cycle lane will be appropriate in Cartagena according to the streets characteristics:

Segregated cycle path on sidewalks. Cycle lanes are partially separated from pedestrian by different pavements, markings and some physical constraints. Provided that the sidewalk width will be enough for both cyclists and pedestrian users, this type of cycle lane could be designed.

Segregated cycle paths on the carriageway. Cycle lanes are partially separated from motor traffic by physical constraints. Provided that the road width was enough for both cyclist and drivers users in a safe way, this type of cycle lane could be designed.

Shared lane cycle path on the carriageway. Cycle lanes are directly painted on the carriageway on narrow and calm streets, because these type of streets are more suitable for traffic calming than for segregated cycle paths.

Minimum measurements of cycle paths as width, protection width when it will be necessary, turning radius or maximum slopes have been pointed out as guideline to design cycle ways (see Table 1). Furthermore, a cycle lane pavement is also selected in order to get a homogeneous cycle network, mainly for segregated cycle paths on sidewalks because cycle paths on the carriageway will be marked on the existing road pavement.

\subsection{Specific design criteria}

The work area for the project, which aim is the connection of campuses by means of a suitable cycle lane network, is clearly defined such as Figure 2 shows. This allows doing detailed studies, which are enumerated below, but the possible solutions of cycle paths are very enclosed. 
Table 1: Minimum measurements of cycle paths for their design.

\begin{tabular}{|l|l|c|}
\hline \multirow{2}{*}{ Width } & Unidirectional & 1.5 meters \\
\cline { 2 - 3 } & Bi-directional & 2.5 meters \\
\hline \multirow{2}{*}{ Protection } & Kerb height $>0.05 \mathrm{~m}$ & 0.5 meters \\
\cline { 2 - 3 } & Close to car parks & $>0.8$ meters \\
\hline \multirow{2}{*}{ Gradient } & Cross axis & $2 \%$ \\
\cline { 2 - 3 } & Longitudinal axis & $<5 \%$ \\
\hline Turning radius & \multicolumn{2}{|c|}{$>10$ meters } \\
\hline
\end{tabular}

\subsubsection{Previous identification of the existing cycle paths}

Their characteristics have been taken into account to the final proposal, without forgetting the homogeneity looked for. As Figure 4 shows, three stretches of cycle ways can be added to the projected cycle network although with some improvements in their routes.

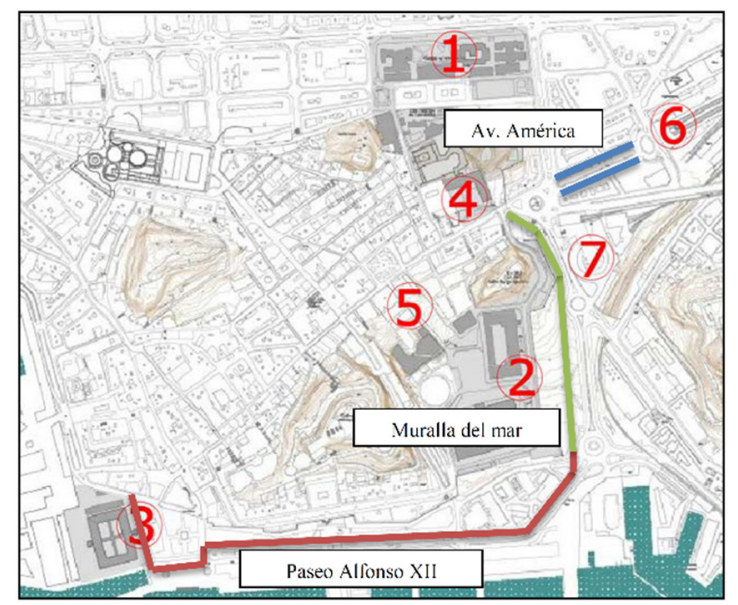

Figure 4: Previous identification of the existing cycle paths.

\subsubsection{Street gradient study}

As Figure 5 shows, 54\% of analysed streets in the work area have a smooth gradient. Only $6 \%$ have a strong gradient. Note that an ascending slope greater than $8 \%$ is considered very uncomfortable by cyclists.

\subsubsection{Cycle route time study}

The trip among campuses and university buildings by cycle lanes has an average time of 4 minutes, taking the larger cycling route about 8 minutes (see Figure 6). Note that, this larger route takes 25 minutes by walking. That is, the new cycle lane network allows fast and efficient movements. 


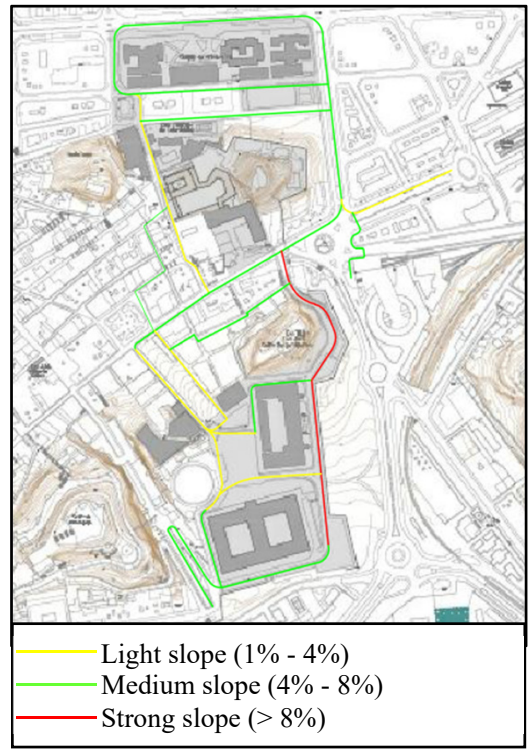

Figure 5: Street gradient study.

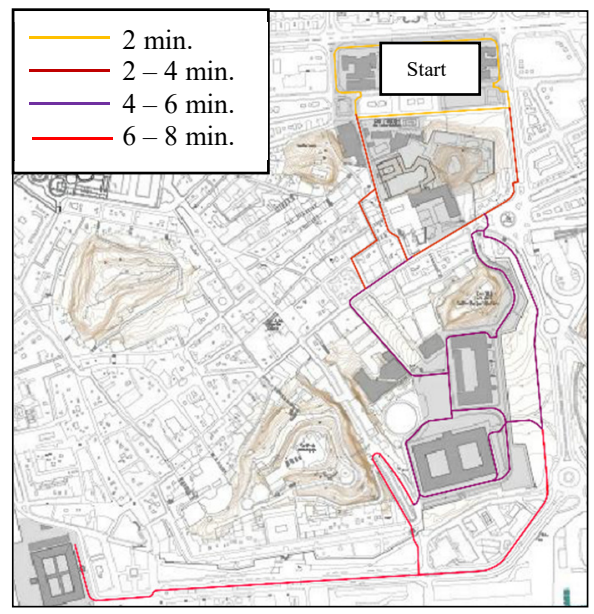

Figure 6: Cycle route time study.

\subsubsection{Street sections study}

Twenty-two street sections in the work area have been analysed to know their measurements and being able to choose the best type of cycle lane for each one. For this study technical datasheet have been made where the measurements and characteristics of each street are indicated together with the suitable type of cycle lane. One example is shown in Figure 7. 


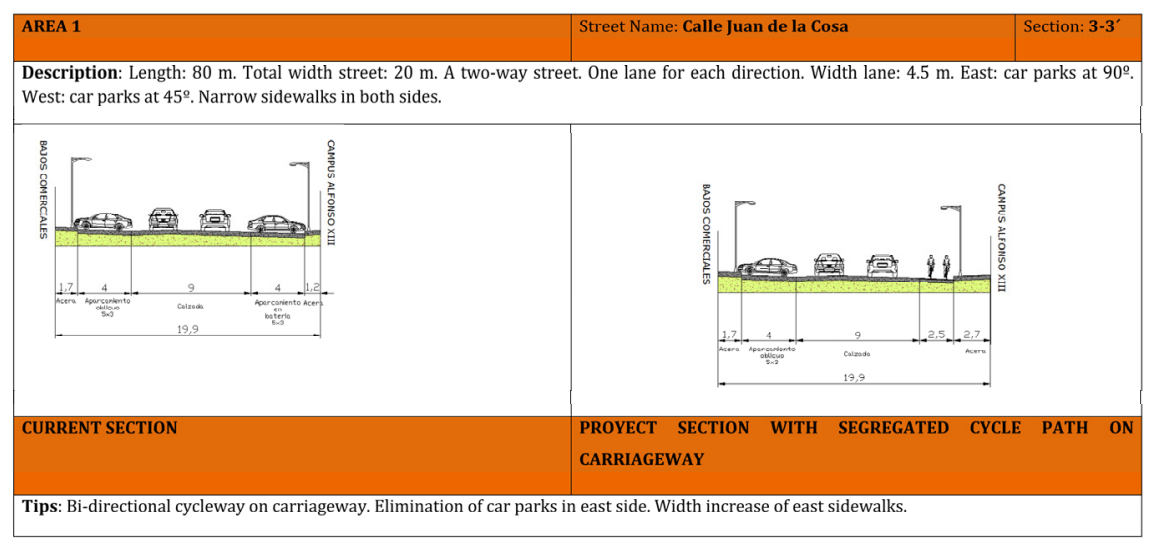

Figure 7: Example of datasheet about street sections.

Once all data were mixed and analysed, and due to the well-defined work area in relation to the points to connect, the main cycle lane network was designed as shown in Figure 8. It is composed of 2300 meters of segregated cycle lane on sidewalks (yellow lines), 240 meters of segregated cycle lane on the carriageway (blue lines) and 180 meters of shared lane on the carriageway (red lines). In this way, 2.7 kilometres of new cycling infrastructure, plus the 1.2 kilometres of existing cycle lanes, the city is supplied with almost 4 kilometres of cycle paths.

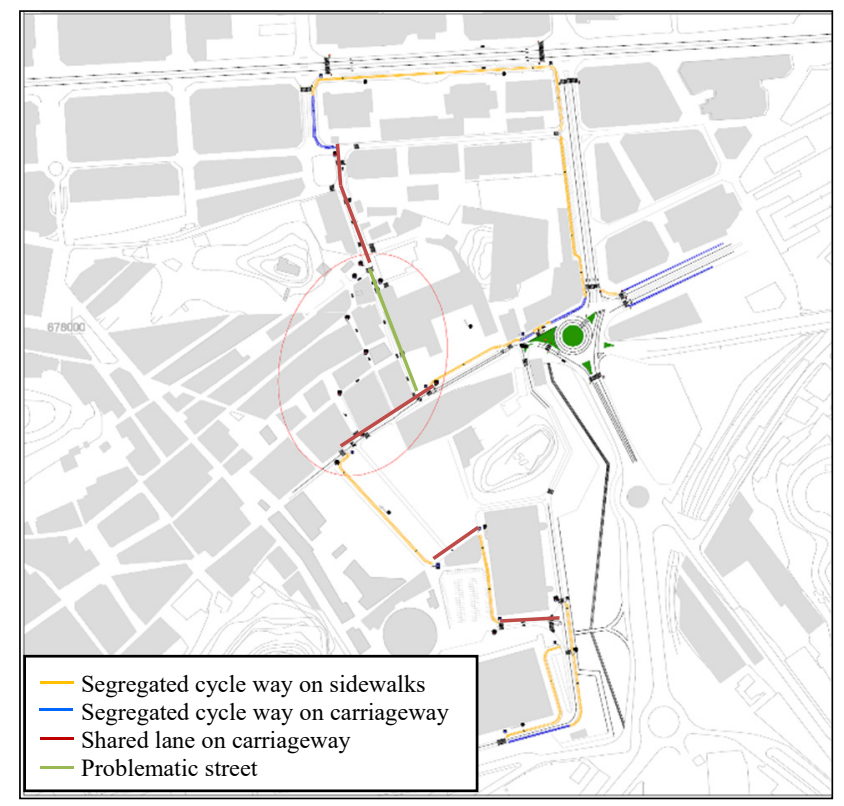

Figure 8: Design of new cycle lane network. 
The only difficulty was the marked stretch of the street inside the red circle in Figure 8 (green line). This narrow street can be divided in two portions. One part, 400 metres length, is two-way street but another part, 300 metres length, is oneway street. Shared lane cycle path on the carriageway is designed at the two-way street (red line) but including a safe bi-directional cycle way in the one-way stretch is more complicated (green line).

To solve this issue three designs were studied and a multicriteria analysis technique was applied to choose the best proposal taking into account route characteristics, traffic segregation, accessibility, safety or cost. Next, these proposals and the multicriteria analysis are briefly explained.

\section{Description of proposals and multicriteria analysis}

\subsection{Proposal 1}

A shared lane cycle path on the carriageway is proposed in the problematic 300 meters (see Figure 9(a)). The main problem is that in these 300 metres drivers travel in one direction but cyclists can ride in both directions, therefore this situation is not very safe for riders.

\subsection{Proposal 2}

An alternative shared lane cycle path on the carriageway is proposed as Figure 9(b) shows. In this way, the problematic stretch is only used by cars (one direction). The new shared streets used by cyclists are also one direction but they are calm streets, with very little traffic. So, proposal two is safer than proposal one from a cyclist point of view. The main inconvenient is the winding cycle path.
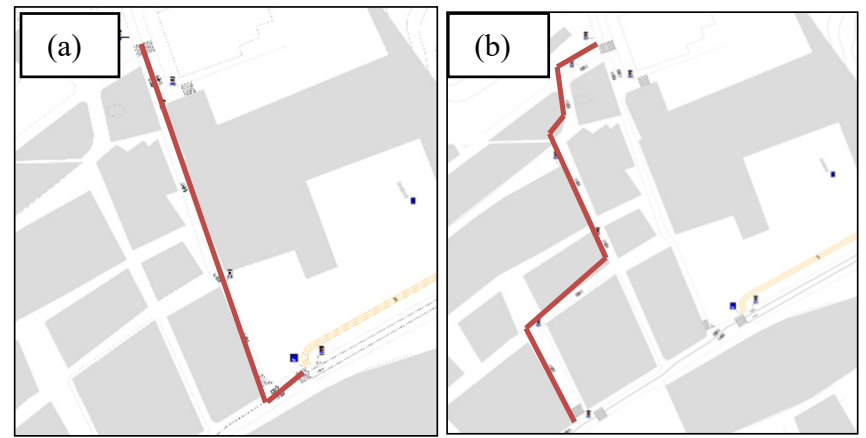

Figure 9: (a) Proposal 1, and (b) Proposal 2, to solve the integration of a cycle path in the detected problematic street.

\subsection{Proposal 3}

In the third proposal a cycle lane is not proposed. That is, the cycle network will not be a close circuit. The problematic street will become a dead-end street for cyclists, who will have to lengthen the itinerary, although it only will be about 5 minutes due to the short distances (see Figure 10). 


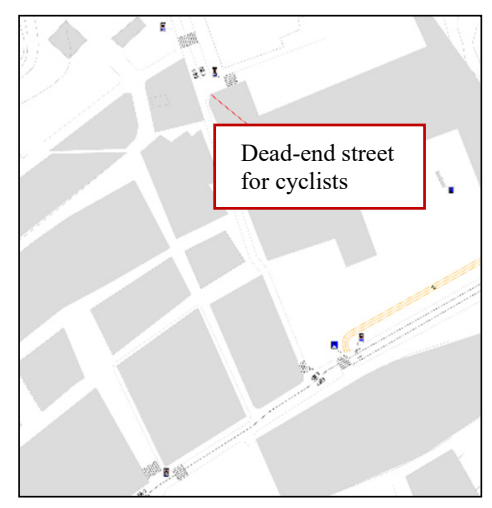

Figure 10: Proposal 3 to solve the integration of a cycle path in the detected problematic street.

Once the three described proposals were analysed, a multicriteria analysis was applied to know the best option for connecting the campuses and others university buildings. The selected items to analyse were:

- Cost;

- Traffic segregation;

- Winding routes;

- Connectivity;

- Safety.

Due to the lack of space the items will not be explained in detail. Only pointing out that cost, connectivity and safety was considering more important than the other two items, traffic segregation and winding routes. After applying the multicriteria analysis technique the proposal 2 was selected.

\section{Description of the selected proposal}

The final proposal is similar to Figure 8 increasing the length of shared lane cycle path on the carriageway in 350 meters. Therefore, the proposed cycle network is composed of 2,300 meters of segregated cycle lane on sidewalks, 240 meters of segregated cycle lane on the carriageway and 530 meters of shared lane cycle path on the carriageway (see Figure 11). In this way, 3 kilometres of new cycling infrastructure, plus the 1.2 kilometres of existing cycle lanes, the city is supplied with 4.2 kilometres of cycle paths. Note that all cycle ways are bi-directional.

In relation to the road surface, segregated cycle lanes on the carriageway and shared lanes on the carriageway keep their road surface, however the surface of segregated cycle lanes on sidewalks will be improved. New cycle ways composed of $15 \mathrm{~mm}$ of graded aggregate and $15 \mathrm{~mm}$ of mass concrete with a superficial protected layer, will be constructed.

A detailed study of intersections, signposts, markers on road surface and location of bicycle parks was also made, however they are not explained here to avoid a long paper. 


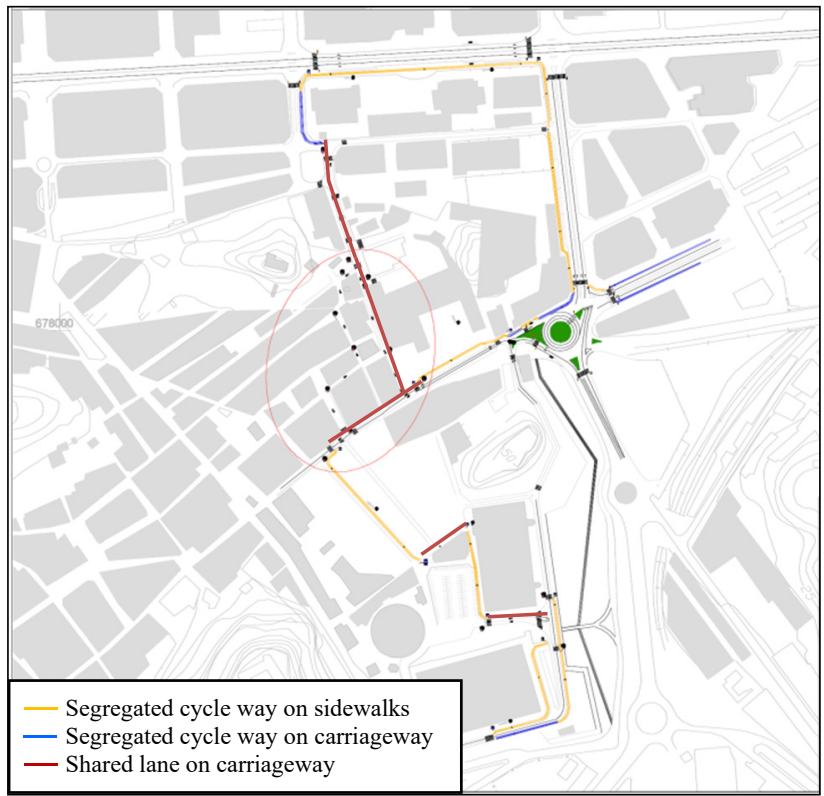

Figure 11: Final design of new cycle lane network.

Finally, the construction of whole network is estimated at 133 days, with an approximate budget of 137,000 euros which distribution correspond to $84 \%$ to construct the segregated cycle lanes on sidewalks, $15 \%$ to construct the segregated cycle lanes on the carriageway, and a $1 \%$ to adapt and mark the shared streets.

\section{Conclusions}

Technical University of Cartagena is worried about sustainability and all its related issues. In relation to mobility, in light of surveys results, it wants to encourage the use of bicycles in the daily mobility among its students, professors and staff members, and this project is the start point. In fact, in a short future, Technical University of Cartagena hopes that a long term bike loan service to its members can be offered, similar to University of Sevilla [10]. Moreover, the chosen proposal was presented to the local government in order to put into practice with its collaboration.

In the near future, a suitable cycle network to connect the different campuses and university buildings will be constructed. Therefore, this efficient and safety cycle network will encourage the use of bicycles among members of university, in a first stage.

However, the final target of this project is to get a correct integration of bicycle in Cartagena. If people see more cyclists in the city, more people will start to ride bike. In this way, road traffic will decrease together with $\mathrm{CO}_{2}$ emissions, among other well-known benefits related to environment and health. Obviously, a global 
and integrated point of view is needed to ensure a right coexistence among all transport modes, although in the same way, to give the first step is also important.

\section{References}

[1] National policies to promote cycling. European Conference of Ministers of Transport (EUCMT), Lubjana 2004. OECD. Online: http://internationaltransportforum.org/pub/pdf/04Cycling.pdf

[2] PROBICI: Guía de la movilidad ciclista. Métodos y técnicas para el fomento de la bicicleta en áreas urbanas. (2010). IDAE Instituto para la Diversificación y Ahorro de la Energía. Madrid: http://www.idae.es/ uploads/documentos/documentos_LibroProBici-GuiaBiciweb1_1_f17cebb2.pdf

[3] Recomendaciones de diseño para las vías ciclistas en Andalucía. 2013. Consejería de Fomento y Vivienda de Andalucía: http://www.juntadeandalucia.es/fomentoyvivienda/estaticas/sites/consejeri a/areas/transportes_infraestructuras/plan_bici/documentos_plan_bici/reco mendaciones_diseno_vias_ciclistas.pdf

[4] Marqués, R., Hernández-Herrador, V. and Calvo-Salazar, M. (2014) Sevilla: a successful experience of bicycle promotion in a Mediterranean context. WIT Transactions on Ecology and the Environment, vol. 191.

[5] Plan Director de Movilidad Ciclista de Vitoria- Gasteiz 2010-2015. Online: http://www.vitoriagasteiz.org/wb021/http/contenidosEstaticos/adjuntos/es/45/63/34563.pdf

[6] Manual para el diseño de vías ciclistas de Cataluña (2008) Generalitat de Catalunya. Departamento de Política Territorial y Obras Públicas. Online: http://territori.gencat.cat/web/.content/home/01_departament/normativa_i_ documentacio/documentacio/territori_mobilitat/transport_public/publicaci ons/manual_per_al_disseny_de_vies_ciclistes_a_catalunya/pdf/vies_ciclist es_cast tcm $32-\overline{4} 5417$.pdf

[7] Dirección General de Tráfico (2000) Manual de recomendaciones de diseño, construcción, infraestructura, señalización, balizamiento, conservación y mantenimiento del carril bici. Madrid.

[8] Carrera, M. A. (2007) Recomendaciones para el proyecto de vías ciclistas. V Congreso Nacional de Seguridad Vial. Valencia.

[9] Manual de aparcamientos de bicicletas. 2007. IDAE Instituto para la Diversificación y Ahorro de la Energía. Madrid: http://www.idae.es/ uploads/documentos/documentos_Manual_de_aparcamientos_de_bicicleta s_edfled0e.pdf

[10] Sistema integral de la bicicleta de la Universidad de Sevilla (SIBUS). Online: http://bicicletas.us.es/?page_id $=5052$ 